\title{
EDITORIAL: OS DESAFIOS DE PUBLICAR PESQUISAS EM EDUCAÇÃO NOS AMBIENTES DIGITAIS
}

v. 20, n. 1, jan./jun. 2018

\section{Cláudia Dias PRIOSTE ${ }^{1}$}

As publicações nos ambientes digitais impõem novos desafios aos editores de revistas científicas e aos pesquisadores da área da educação: de um lado, oferecem-nos uma gigantesca amplitude de possibilidades e de visibilidade, de outro, há o risco de que as pesquisas se percam na nuvem estratosférica de informações, nem sempre relevantes. Além disso, urge a necessidade de refletir sobre as exigências de produtivismo e suas repercussões na qualidade das produções acadêmicas de âmbito educacional.

A revista Doxa, no último ano, se lançou ao desafio de ampliar sua visibilidade nos ambientes digitais, de melhorar seu design gráfico e aprimorar a organização de seus artigos, reafirmando seu sólido compromisso com a divulgação de pesquisas científicas de qualidade no âmbito da Psicologia e da Educação. Nessa edição, comemoramos algumas conquistas obtidas com muito empenho e esforço, especialmente no que concerne às indexações nas seguintes plataformas nacionais e internacionais: Associação Brasileira de Editores Científicos (ABEC); Google Scholar; Periódicos Livre Acesso (LivRe); Sumários de Revistas Brasileiras; Citas Latinoamericanas em Ciencias Sociales y Humanidades (CLASE); Latindex; Diadorim; Periódicos CAPES; Red Iberoamericana de Innovación y Conocimiento Científico (REDIB); Bibliografia Brasileira de Educação (BBB); Directory of Research Journals Indexing (DRJI); Universitat Vechta; e Directory of Open Access Journals (DOAJ).

O que representam tais indexações? Para que elas servem? Resumidamente, as indexações nos possibilitam ampliar consideravelmente a visibilidade de nossos artigos e aumentar o número de citações, elevando-nos a um novo patamar editorial, com maiores repercussões acadêmicas dos trabalhos publicados nacional e internacionalmente. Contudo, o credenciamento nas plataformas indexadas obriga-nos a um constante aprimoramento em

1 Universidade Estadual Paulista (UNESP), Araraquara - SP - Brasil. Docente do Programa de Pósgraduação em Educação Escolar. Departamento de Psicologia Da Educação. ORCID: <https://orcid.org/0000-0001-6824-3410>. E-mail: claudiaprioeste@fclar.unesp.br 
função das exigências atribuídas pelas convenções internacionais de publicações científicas. Com uma profusão de periódicos científicos, as instituições indexadoras vão se tornando mais seletivas e adotam critérios rigorosos para manter os periódicos indexados.

Rigor e critérios bem definidos para a análise dos periódicos, bem como apreciação das contribuições científicas das publicações selecionadas pelos editores, se tornam cada vez mais importantes, principalmente em um cenário competitivo, cuja lógica produtivista pode induzir a proliferação de revistas predatórias, que adotam condutas duvidosas para disseminar suas produções.

A análise de Rego (2014) sobre o produtivismo e a comunicação de pesquisas nos traz algumas contribuições para refletirmos sobre os desafios das publicações em Educação. A autora fundamenta-se na perspectiva do pharmakon de Platão, retomado por Derrida (2005) para destacar a antinomia de veneno e remédio quanto à escrita. Transpondo essa ideia para o debate sobre publicações científicas, nos vemos diante da imperativa necessidade de divulgarmos as pesquisas por meio de comunicações científicas on-line, e ao mesmo tempo, corremos o risco de seus efeitos adversos em decorrência da excessiva valorização quantitativa das publicações. O produtivismo acadêmico refere-se, assim, à lógica de avaliar o trabalho do pesquisador a partir, exclusivamente, da quantidade de publicações em periódicos. Os sintomas perversos dessa lógica, inspirada nas ciências duras, incluem uma busca frenética por espaços editoriais, a endogenia das revistas, a falta de ética em pesquisa, bem como a relativização dos critérios de qualidade.

Nesse contexto, precisamos retomar e reafirmar a importância da qualidade nas pesquisas em educação, e isso passa, a priori, pelo questionamento do que é uma pesquisa acadêmica e do que vale a pena ser divulgado, sem perder de vista a multiplicidade de perspectivas teóricas e empíricas que podem contribuir para elucidar determinados problemas. Nesse sentido, retomamos a proposta de Beillerot (1991) sobre as condições necessárias para uma pesquisa acadêmica: "uma produção de conhecimentos novos (critério 1); um rigor nos procedimentos de investigação (critério 2); e uma comunicação de resultados (critério 3)" (p. 19, tradução nossa). Na visão do autor, tais condições constituem um primeiro patamar básico, necessário a todas as pesquisas. Um segundo nível, proposto por ele, envolve os seguintes critérios: introdução de uma dimensão crítica e reflexiva sobre as fontes de pesquisa; organização e sistematização dos dados obtidos e, por fim, uma interpretação e análise criteriosa dos dados, com base em teorias academicamente reconhecidas. 
Com relação ao último critério adotado por Beillerot (1991), precisamos de cautela no que concerne à nossa tradição colonialista de reverenciar teorias eurocêntricas. Não estaria na hora de nos arriscarmos em novas teorias construídas a partir da dimensão empírica e reflexiva de nosso contexto educacional? Uma perspectiva interessante de pesquisa, e que pode nos ajudar no processo de decolonização teórica é a abordagem da Teoria Fundamentada, pouco explorada ainda no âmbito educacional. A Teoria Fundamentada pode ser definida como um "projeto de pesquisa qualitativo em que o investigador gera uma explicação geral (uma teoria) de um processo, uma ação ou uma interação moldada pelas visões de um grande número de participantes" (CRESWELL, p. 72). É essencial que os pesquisadores em educação comecem a explorar novas metodologias, se atualizem e ousem desenvolver novos repertórios teóricos fundamentados empiricamente na realidade brasileira.

Outro aspecto importante a ser destacado quando se trata de pesquisa em educação, e que pode ter origem em nossas bases conceituais eurocêntricas, refere-se à quantidade de estudos publicados com a finalidade de afirmar determinado ponto de vista, modismo metodológico e teórico, ou determinadas ideologias difundidas em estilo acadêmicocientífico.

É evidente que os pesquisadores partem de determinadas premissas teóricas, de um conjunto de ideias que contribuem para a formulação de suas hipóteses iniciais. Esse conjunto de ideias, podendo ser chamado de ideologias, também possui a dimensão do pharmakon, atuando como remédio e veneno. Remédio, pois os conhecimentos prévios e as ideias são importantes fundamentos organizadores da pesquisa. Veneno, se tais ideias servirem como justificativas que sustentam determinadas desigualdades sociais, que estão a serviço da manutenção do poder das classes dominantes. Chauí observa que "através da ideologia, são montados um imaginário e uma lógica de identificação social com a função precisa de escamotear o conflito, dissimular a dominação e ocultar a presença do particular" (p. 21). Nesse sentido, é essencial analisar o quanto determinadas modas teóricas não estão servindo para dissimular estruturas de poder e manipulação das massas.

Slavin (2008) considera que, "na história da educação, a adoção de programas instrucionais e práticas têm sido conduzidas por ideologias, modismos, políticas e marketing, mais do que por evidências”. Portanto, não é apenas privilégio do Brasil a inundação de pesquisas, programas e políticas públicas formuladas mais por convicções e modismos do que fundamentadas em evidências científicas. O produtivismo pode acentuar 
essa característica fazendo com que as convicções falem mais alto do que as evidências, o que pode resultar em pesquisas enviesadas, com efeitos cumulativos devastadores, dificultando assim, o avanço em uma área crítica que é a Educação. Por isso, é recomendável que os pesquisadores reflitam sobre o viés ideológico de suas pesquisas, duvidem, questionem sobre as melhores metodologias, analisem criteriosamente seus resultados, e estejam abertos para o valor eurístico de suas investigações.

Além disso, cabe alertar para o cuidado com o narcisismo científico, o qual pode ofuscar o pesquisador, fazendo com que ele não se atente aos limites de seu estudo, para a qualidade de seu trabalho, e não esteja aberto às críticas que são realizadas pelos pareceristas dos periódicos ou por seus pares.

Considerando esses fatores, seguem algumas questões que podem servir de parâmetros para analisar as publicações antes que sejam enviadas às revistas:

- Os conceitos principais do trabalho estão bem delimitados? O problema da pesquisa e os objetivos estão bem explicitados?

- A revisão de literatura revela um bom domínio do que tem sido pesquisado, nos últimos anos, no campo de estudo? Indica lacunas de pesquisas que justificam o estudo proposto?

- Os procedimentos metodológicos estão bem descritos?

- Os resultados trazem contribuições novas ou interessantes para o campo de estudo?

- Os tópicos estão bem articulados?

- A escrita está condizente com as normas do idioma e da linguagem acadêmica?

- As argumentações e conclusões são coesas e claras?

Para finalizar, considerando a perspectiva do pharmakon, primeiramente como remédio: os ambientes digitais são importantes espaços para visibilidade global de pesquisas educacionais, as quais outrora se restringiam à divulgação local e nacional em periódicos impressos. As exigências de indexações internacionais podem contribuir para melhorar a qualidade das publicações nacionais. No entanto, em relação ao lado "venenoso", o excesso de informações, a pressa, o narcisismo acadêmico, a competitividade e o produtivismo podem promover a proliferação de pesquisas repetitivas, sem originalidade, com fundamentação teórica duvidosa ou de baixa relevância científica. 


\section{REFERÊNCIAS}

BEILLEROT, Jacques. La "recherche": essai d'analyse. Recherche et Formation, Paris, v. 09, p. 17-31, abril/1991.

CHAUÍ, Marilena. Cultura e democracia: o discurso competente e outras falas. São Paulo: Cortez Editora, 2003.

CRESWELL, John W. Investigação Qualitativa e Projeto de Pesquisa: Escolhendo entre Cinco Abordagens, $3^{\mathrm{a}}$ Ed. Penso, 2014. VitalBook file.

DERRIDA, Jacques Derrida. A farmácia de Platão. São Paulo: Iluminuras, 2005.

REGO, Tereza C. Produtivismo, pesquisa e comunicação científica: entre o veneno e o remédio. Educ. Pesqui., São Paulo, v. 40, n. 2, p. 325-346, abr./jun. 2014. ISSN:

SLAVIN, Robert E. Perspective en Evidencre-Based Rechearch in Education.

Educacional Rechearcher, Thousand Oaks, v. 37, n. 1, p. 5-14, 2008. ISSN-0013-189X.

\section{Como referenciar este artigo}

PRIOSTE, Cláudia Dias. Os desafios de publicar pesquisas em educação nos ambientes digitais. Doxa: Rev. Bras. Psico. e Educ., Araraquara, v. 20, n. 1, p. 1-5, jan./jun., 2018. e-ISSN: 2594-8385. DOI: 10.30715/rbpe.v20.n1.2018.11500

Submetido em: 01/06/2018

Aprovado em: 01/06/2018 